\title{
The effect of $\mathrm{Nd}$ :YAG laser treatment of posterior capsule opacification on anterior chamber depth and refraction in pseudophakic eyes
}

This article was published in the following Dove Press journal:

Clinical Ophthalmology

25 March 2015

Number of times this article has been viewed

\author{
Bharkbhum Khambhiphant ${ }^{\prime}$ \\ Chayata Liumsirijarern² \\ Piyada Saehout'
}

'Department of Ophthalmology, King Chulalongkorn Memorial Hospital, Thai Red Cross Society, ${ }^{2}$ Department of Ophthalmology, Faculty of

Medicine, Chulalongkorn University, Bangkok, Thailand
Correspondence: Bharkbhum Khambhiphant

Department of Ophthalmology, King Chulalongkorn Memorial Hospital, Thai Red Cross Society, Bangkok 10330, Thailand

Tel +66898 III 573

Fax +6622528290

Email bharkbhum@gmail.com
Purpose: This was a prospective descriptive study to determine the changes in intraocular lens (IOL) position after neodymium-doped yttrium-aluminum-garnet (Nd:YAG) laser posterior capsulotomy by measuring anterior chamber depth (ACD) and refraction, including the spherical equivalent (SE) and cylinder.

Materials and methods: Forty-seven pseudophakic eyes with posterior capsule opacification of 29 patients were included. Nd:YAG laser posterior capsulotomy was performed. Patients' ACD and refraction were measured before the treatment, as well as after the treatment at 1 week and 3 months. IOLMaster ${ }^{\circledR}$ and an automated refractometer were used at the Department of Ophthalmology, King Chulalongkorn Memorial Hospital, Bangkok, Thailand.

Results: There were no statistically significant differences in ACD and SE before and after laser treatment at 1 week and 3 months (repeated analysis of variance, $P=0.582$ and $P=0.269$, respectively). Both backward IOL movement (number $[n]=29)$ and forward IOL movement $(n=18)$ were found. Some changes in cylindrical refraction were found at 1 week, but decreased at 3 months after capsulotomy (baseline cylinder: -1.16 ; cylinder at 1 week and 3 months: -1.00 and -1.14 , respectively; $P=0.012$ ). These changes were the same with one-piece and three-piece IOLs.

Conclusion: Nd:YAG laser posterior capsulotomy did not significantly change ACD and SE. It led to cylinder change at 1 week after laser, but the effect decreased at 3 months. This effect was small and may not be clinically significant.

Keywords: posterior capsule opacification, neodymium-doped yttrium-aluminum-garnet, anterior chamber depth, pseudophakia, refraction

\section{Introduction}

Posterior capsular opacification (PCO) is the most common long-term complication of cataract surgery in both phacoemulsification and extracapsular cataract extraction (ECCE). The incidences of PCO were $11.8 \%$ at 1 year, $20.7 \%$ at 3 years, and $28.4 \%$ at 5 years after surgery. ${ }^{1}$ Fortunately, the overall incidence of PCO and the incidence of neodymium-doped yttrium-aluminum-garnet (Nd:YAG) laser posterior capsulotomy has decreased from $50 \%$ in the 1980 s and early 1990 s to less than $10 \%$ today. ${ }^{2,3}$ Some patients experience significant vision complications including visual acuity, glare, and contrast sensitivity, which often require further treatment. Currently, the standard treatment for PCO is Nd:YAG laser posterior capsulotomy, which has a success rate of more than $95 \% .^{2}$

Reported complications of Nd:YAG laser posterior capsulotomy include elevated intraocular pressure, iritis, corneal damage, intraocular lens (IOL) damage, cystoid 
macular edema, disruption of the anterior hyaloid surface, increased risk of retinal detachment, and IOL movement or dislocation. ${ }^{4,5}$ In some patients, a refraction change was noticed after Nd:YAG laser posterior capsulotomy, but proving this remains difficult.

Petersen et $\mathrm{al}^{6}$ reported four cases of posterior silicone haptic IOL dislocation after Nd:YAG laser posterior capsulotomy at a mean of 16 months after treatment. Several studies have demonstrated IOL movement after laser treatment in a different manner; Findl et $\mathrm{al}^{7}$ reported backward IOL movement and hyperopic shift. Also, larger capsulotomy size induces greater backward movement. ${ }^{7,8}$ Conversely, other studies reported a progressive decrease in anterior chamber depth (ACD) or no IOL movement at all, with no findings of statistically significant changes in the patients' refraction. $^{9-14}$

Any significant change in IOL position can lead to a change in the patient's refractive status, which will therefore require corrective lens prescriptions. The purpose of this study was to determine the changes of IOL position after Nd:YAG laser posterior capsulotomy by measuring both ACD using a slit illumination technique, IOLMaster ${ }^{\circledR}$ (Carl Zeiss Meditec AG, Jena, Germany), and changes in patient refractions using an automated refractometer (Topcon KR-8800; Topcon Corporation, Tokyo, Japan).

\section{Materials and methods}

This was a prospective descriptive study. All research and measurements followed the World Medical Association's Declaration of Helsinki. Written informed consent was obtained from all of the patients before the interventions were performed. The research protocol was approved by the institutional review boards of Chulalongkorn University (Bangkok, Thailand) and registered with the Thai Clinical Trial Registry (TCTR20130000006).

\section{Enrollment}

Twenty-nine pseudophakic patients were enrolled between July 2012 and March 2013, and follow-up was completed in June 2013. This study was conducted at the Department of Ophthalmology, Faculty of Medicine, Chulalongkorn University. Patients were eligible for study entry if there was any presence of the loss of more than one best-corrected visual acuity (BCVA) Snellen line at postoperative examination with visual deterioration due to PCO (impaired visual acuity, glare, and reduced contrast sensitivity), and if they needed Nd:YAG laser treatment. All patients had undergone cataract surgery (phacoemulsification in 45 eyes and ECCE in two eyes) with anterior capsulorhexis and anterior capsulotomy in ECCE cases with in-the-bag IOL implantation by the surgeon (BK).

Exclusion criteria included complications during cataract surgery or during the postoperative period; the presence of other significant uncontrolled diseases, such as diabetes with poor glycemic control and ophthalmic diseases; those who had undergone any other ophthalmic surgeries prior to $\mathrm{Nd}$ :YAG laser posterior capsulotomy treatment; as well as patients who could not maintain an upright position during the procedure.

Complete ocular examinations, including slit-lamp biomicroscopic and fundus examinations, were performed. ACD (calculated average ACD after four measurements) and patient refractions were measured using IOLMaster and the automated refractometer (Topcon KR-8800) by two technicians (one for ACD measurement and one for autorefraction). All data were collected from nondilated eyes prior to Nd:YAG laser posterior capsulotomy at 1 week and 3 months after the procedure.

The posterior capsulotomies were performed by the same surgeon $(\mathrm{BK})$ in a single session with a $\mathrm{Nd}$ :YAG laser, Visulas YAG III (Carl Zeiss Meditec AG), and a contact lens (Abraham capsulotomy lens) with an average diameter of $5.0 \mathrm{~mm}$ crisscross pattern, as shown in Figure 1.

The Nd:YAG laser was posterior defocused by $0.50 \mathrm{~mm}$ in every eye. The energy level, total spot count, and total energy use of each patient were recorded. All study patients received

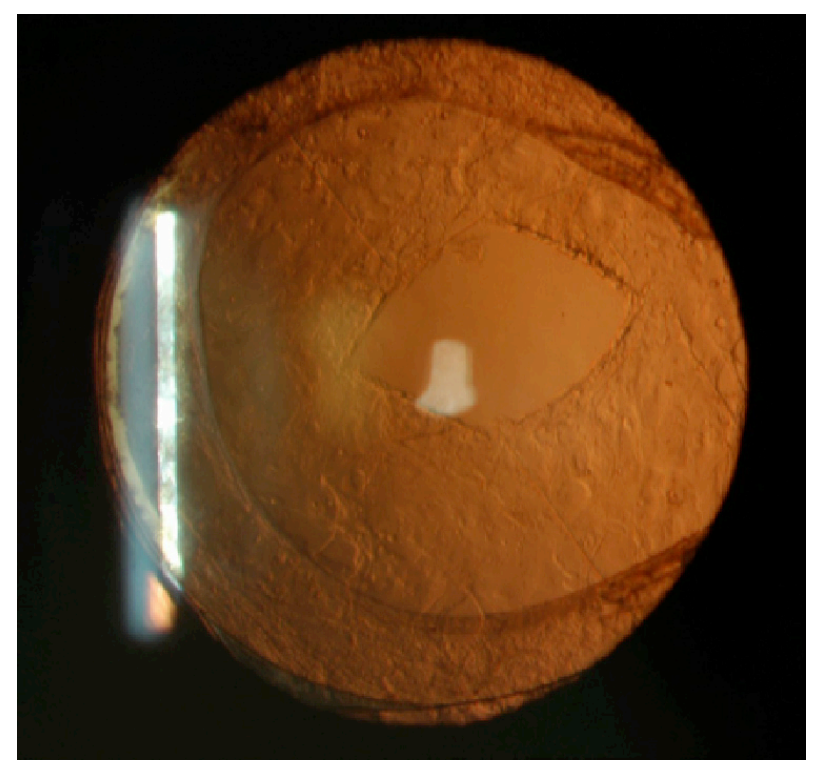

Figure I Anterior segment photography immediately after Nd:YAG laser posterior capsulotomy (430×407).

Abbreviation: Nd:YAG, neodymium-doped yttrium-aluminum-garnet. 
a standard medical regimen after laser $(0.1 \%$ brimonidine eye drop, one drop immediately after laser; and fluorometholone eye drop, four times a day for 1 week).

The primary study outcomes were ACD and patient refraction change. All patients had outcome assessments performed before laser treatment, and 1 week and 3 months after treatment.

All data were analyzed statistically by repeated analysis of variance and paired $t$-tests using SPSS version 17.0. Changes in patient refractions in terms of spherical and cylindrical powers were compared separately. Analyses of cylindrical power excluding the axis were performed. In all cases, $P$-values $<0.05$ were considered significant.

\section{Results}

Of the 47 operative eyes, 45 had phacoemulsification and two had ECCE with in-the-bag IOL implantation (two had one-piece poly[methyl methacrylate] IOLs, 22 had threepiece foldable acrylic IOLs, and 23 had one-piece foldable acrylic IOLs).

The patients' ages ranged from 44-86 years (mean: 68.4 years). The average interval from surgery to capsulotomy was 28.3 months (range: 5-71 months).

The mean energy use for laser treatment was $0.8 \mathrm{~mJ} / \mathrm{spot}$; the average total spot count was 15.4 (range: 7-39), and the total energy level was $12.6 \mathrm{~mJ}$ (range: 5.6-29.5 mJ).

No serious complications after treatment were observed. The patient characteristics are shown in Table 1 .

\section{Anterior chamber depth}

The mean ACD was found to increase over time, but the changes were not statistically significant $(P=0.58)$, as shown in Table 2. In the subgroup analysis, ACD increased in 29 patients (range: $0.01-1.22 \mathrm{~mm}$ ) and decreased in 18 patients (range: $-0.07 \mathrm{~mm}$ to $-1.13 \mathrm{~mm}$ ) after 3 months

Table I Patients' characteristics

\begin{tabular}{llll}
\hline & Mean & Range & SD \\
\hline Age (years) & 68.4 & $44-86$ & 8.9 \\
Time interval for cataract surgery & 28.3 & $5-7 \mid$ & 14.9 \\
to capsulotomy (months) & & & \\
Types of IOLs (number of eyes) & & & \\
$\quad$ One-piece foldable & 23 & & \\
$\quad$ Three-piece foldable & 22 & & \\
$\quad$ One-piece PMMA & 2 & & 5.4 \\
Energy level (mJ) & 0.8 & & 6.7 \\
Total energy use (mJ) & 12.6 & $5.6-29.5$ & $7-39$ \\
Total spot count (number) & 15.4 & $7-4$ & \\
\hline
\end{tabular}

Abbreviations: SD, standard deviation; IOL, intraocular lens; PMMA, poly(methyl methacrylate). of laser. The mean increase was $0.36 \mathrm{~mm}$ and the mean decrease was $-0.37 \mathrm{~mm}$.

\section{Spherical change}

There were no significant differences between the mean spherical equivalent (SE) refraction before laser treatment, and after laser at 1 week and 3 months $(P=0.27)$, as shown in Table 3.

\section{Cylindrical change}

There were statistically significant differences between cylindrical power refractions before and 1 week after laser was performed $(P=0.008)$, but no significant differences at 3 months after laser $(P=0.58)$, as shown in Table 4 .

\section{IOL styles (one-piece and three-piece)}

Table 5 shows the changes in the SE, cylinder, and ACD at 3 months associated with the different IOL styles. The onepiece IOLs showed more pronounced changes in the SE and cylinder, and the three-piece IOLs showed more backward movement of ACD; however, no statistical significance was found.

\section{Discussion}

A total of 47 eyes were included and analyzed in this study. The mean time from cataract surgery to the Nd:YAG laser posterior capsulotomy treatment of PCO was 28.3 months (range: 5-71 months). The same intended energy of the laser $(0.8 \mathrm{~mJ} / \mathrm{spot})$ and size of the posterior capsulotomy were used for every patient (average size: $5 \mathrm{~mm}$ ). However, there were variations in the posterior capsulotomy size spot counts (7-39 spots), which required total energy (5.6-29.5 mJ).

Current cataract surgeries require precise IOL positions to give the best refractive results, especially in premium IOLs. Thus, movement of the IOL after PCO treatment can cause refractive change and visual quality decline. We measured IOL movement by comparing ACD using partial

Table 2 ACD over time

\begin{tabular}{llll}
\hline & \multicolumn{2}{l}{ ACD $(\mathbf{m m})$} & \\
\cline { 2 - 4 } & $\begin{array}{l}\text { Before } \\
\text { laser }\end{array}$ & $\begin{array}{l}\text { After laser, } \\
\text { I week }\end{array}$ & $\begin{array}{l}\text { After laser, } \\
\mathbf{3} \text { months }\end{array}$ \\
\hline Mean (SD) & $3.74(0.38)$ & $3.79(0.48)$ & $3.82(0.48)$ \\
Difference & & 0.05 & 0.08 \\
Changes (\%) & & $1.3 \%$ & $2.2 \%$ \\
$P$-value* & & 0.58 & 0.26 \\
\hline
\end{tabular}

Notes: *Paired $t$-test compared with ACD before treatment. Repeated analysis of variance; $P$-value $=0.58$.

Abbreviations: ACD, anterior chamber depth; SD, standard deviation. 
Table 3 SE over time

\begin{tabular}{llll}
\hline & \multicolumn{2}{l}{ SE (diopters) } & \\
\cline { 2 - 4 } & $\begin{array}{l}\text { Before } \\
\text { laser }\end{array}$ & $\begin{array}{l}\text { After laser, } \\
\text { I week }\end{array}$ & $\begin{array}{l}\text { After laser, } \\
\text { 3 months }\end{array}$ \\
\hline Mean (SD) & $-0.19(0.52)$ & $-0.24(0.50)$ & $-0.21(0.54)$ \\
Difference & & -0.06 & -0.02 \\
Change (\%) & & $32.4 \%$ & $10.8 \%$ \\
P-value* & & 0.09 & 0.52 \\
\hline
\end{tabular}

Notes: *Paired $t$-test compared with SE before treatment. Repeated analysis of variance; $P$-value $=0.27$.

Abbreviations: SE, spherical equivalent; SD, standard deviation.

coherence interferometry of the IOLMaster. Although ACD appeared to increase in our study, there was no indication of any statistical significance. In our subgroup analysis, we found both backward and forward movement of the IOL in 29 and 19 patients, respectively. We controlled the effects of mydriasis on IOL positions by measuring ACD in the nonmydriatic state. One disadvantage, however, was we found that errors related to the precise evaluation of the ACD can occur because of interfering signals reflected by the surface, particularly on the anterior IOL surface. For further study, we suggest using different methods (optical coherence tomography or ultrasound biomicroscopy) for more precise ACD measurement. ${ }^{15,16}$

Another measured outcome in this study was the refractive change caused by Nd:YAG laser posterior capsulotomy. It is important to know whether refractive changes occur after laser treatment to best determine the appropriate time periods for new corrective lens prescriptions for patients. As for the SE, no statistically significant changes were found, but at 1 week after laser, there were cylindrical changes that decreased after 3 months' time. It is therefore suggested that corrective lenses can be prescribed after 3 months, once the cylindrical change has decreased. However, the shift in refraction (both SE and cylinder) was small enough that it may not be clinically relevant.

We also tried to find relationships between the types of IOL (one-piece and three-piece IOL) and SE, cylindrical,

Table 4 Cylindrical power over time

\begin{tabular}{llll}
\hline & \multicolumn{2}{l}{ Cylindrical power (diopters) } \\
\cline { 2 - 4 } & $\begin{array}{l}\text { Before } \\
\text { laser }\end{array}$ & $\begin{array}{l}\text { After laser, } \\
\text { I week }\end{array}$ & $\begin{array}{l}\text { After laser, } \\
\text { 3 months }\end{array}$ \\
\hline Mean (SD) & $-1.16(0.69)$ & $-1.00(0.65)$ & $-1.14(1.06)$ \\
Difference & & 0.16 & 0.02 \\
Changes (\%) & & $13.8 \%$ & $2.1 \%$ \\
P-value* & & 0.008 & 0.58 \\
\hline
\end{tabular}

Notes: *Paired $t$-test compared with cylindrical power before treatment. Repeated analysis of variance; $P$-value $=0.01$.

Abbreviation: SD, standard deviation. and ACD changes, but again, there were no significant differences. Some studies found that the larger the capsulotomy size, the more pronounced the IOL movement; ${ }^{7,8}$ however, in our study, we controlled the size of the openings to approximately $5.0 \mathrm{~mm}$ in every patient.

Previous studies have shown inconclusive results regarding IOL position changes after the laser treatment of PCO. Zaidi and Askari ${ }^{12}$ found that Nd:YAG laser posterior capsulotomy treatment causes anterior IOL displacement, which could result from a pushing effect of the shockwaves from the posterior focus mode of the laser and hyperopic shift of SE. $\mathrm{Hu}$ et $\mathrm{al}^{10}$ and Ozkurt et a $\mathrm{l}^{14}$ reported no significant changes of ACD and SE after Nd:YAG laser treatment. In contrast with Findl et $\mathrm{al}^{7}$ backward movement and ACD changes were found in every patient. In our study, both backward and forward movements of the IOL positions were present, which warrants further study.

A positive point of our study is that we controlled the capsulotomy size and energy that was used (but variations still occurred due to the individual thickness of PCO). In this study, we performed posterior capsulotomy earlier in some cases; the criterion for this included visual deterioration when the loss of $\geq 1$ BCVA Snellen line was detected. The power used during the laser procedure might be lower than in other studies, and it depends on the thickness of the PCO. In cases with a thicker PCO, more energy may be required to break the posterior capsule, and this might affect the ACD. ACD was measured by the same practitioner in every patient and all patients were examined in a nonmydriatic state.

That we measured the ACD in a nonmydriatic state might be a possible source of difference, because the patient's age and pseudoaccommodation could be confounding factors. ${ }^{17,18}$ Axial biometry may not provide sufficient information regarding IOL alignment, so it is better to describe the IOL position three-dimensionally, especially given that tilting and decentration of the IOL might also affect the ACD and refraction outcomes.

Further studies to compare loop-haptic and plate-haptic effects on IOL positions, to assess alternative ACD measurement techniques (anterior segment optical coherence tomography, Scheimpflug camera, or ultrasound), in addition to the recruitment of a larger patient population will shed more light on the subject.

\section{Conclusion}

In conclusion, we found no statistically significant changes in ACD and SE after Nd:YAG laser posterior capsulotomy. However, cylindrical changes were found at 1 week after 
Table 5 Types of IOL and SE, cylinder, and ACD change at 3 months

\begin{tabular}{llll}
\hline Type of IOL & Mean SE change (SD) & Mean cylinder change (SD) & Mean ACD change (SD) \\
\hline One-piece (25 eyes) & $-0.06(0.30)$ & $0.06(0.35)$ & $0.06(0.52)$ \\
Three-piece (22 eyes) & $0.01(0.20)$ & $-0.01(0.30)$ & $0.11(0.47)$ \\
$P$-value (independent $t$-test) & 0.32 & 0.25 & 0.71 \\
\hline
\end{tabular}

Abbreviations: IOL, intraocular lens; SE, spherical equivalent; $A C D$, anterior chamber depth; SD, standard deviation.

treatment, but these decreased at 3 months. The changes were the same with one-piece and three-piece IOLs.

\section{Acknowledgments}

This study was supported by the Ratchadapiseksompotch Research Fund, Faculty of Medicine, Chulalongkorn University, Bangkok, Thailand. This paper was presented on Friday November 1, 2013 at the 32nd Annual Scientific Meeting of the Royal College of Ophthalmologists of Thailand; Le Meridian Hotel; Chiangmai, Thailand.

\section{Disclosure}

The authors report no conflicts of interest in this work.

\section{References}

1. Schaumberg DA, Dana MR, Christen WG, Glynn RJ. A systematic overview of the incidence of posterior capsule opacification. Ophthalmology. 1998;105(7):1213-1221.

2. Pandey SK, Apple DJ, Werner L, Maloof AJ, Milverton EJ. Posterior capsule opacification: a review of the aetiopathogenesis, experimental and clinical studies and factors for prevention. Indian J Ophthalmol. 2004;52(2):99-112.

3. Bhargava R. A review of posterior capsule opacification. Int J Ophthalmic Pathol. 2014;3:4.

4. Billotte C, Berdeaux G. Adverse clinical consequences of neodymium:YAG laser treatment of posterior capsule opacification. $J$ Cataract Refract Surg. 2004;30(10):2064-2071.

5. Aslam TM, Devlin H, Dhillon B. Use of Nd:YAG laser capsulotomy. Surv Ophthalmol. 2003;48(6):594-612.

6. Petersen AM, Bluth LL, Campion M. Delayed posterior dislocation of silicone plate-haptic lenses after neodymium:yag capsulotomy. $J$ Cataract Refract Surg. 2000;26(12):1827-1829.

7. Findl O, Drexler W, Menapace R, et al. Changes in intraocular lens position after neodymium: YAG capsulotomy. J Cataract Refract Surg. 1999;25(5):659-662.
8. Hu CY, Woung LC, Wang MC. Change in the area of laser posterior capsulotomy: 3 month follow-up. J Cataract Refract Surg. 2001;27(4): $537-542$.

9. Thornval P, Naeser K. Refraction and anterior chamber depth before and after neodymium: YAG laser treatment for posterior capsule opacification in pseudophakic eyes: a prospective study. J Cataract Refract Surg. 1995;21(4):457-460.

10. Hu CY, Woung LC, Wang MC, Jian JH. Influence of laser posterior capsulotomy on anterior chamber depth, refraction, and intraocular pressure. J Cataract Refract Surg. 2000;26(8):1183-1189.

11. Chua CN, Gibson A, Kazakos DC. Refractive changes following Nd:YAG capsulotomy. Eye (Lond). 2001;15(Pt 3):304-305.

12. Zaidi M, Askari SN. Effect of Nd:YAG laser posterior capsulotomy on anterior chamber depth, intraocular pressure, and refractive status. Asian Journal of Ophthalmology. 2003;5(4):2-5.

13. Evicman T, Ozkurt Y, Sengor T, Haboglu M, Kurna S, Aki S. Anterior chamber depth changes and complications after Nd:YAG laser treatment for posterior capsule opacification in pseudophakic eyes. Acta Ophthalmol. 2007;85(Suppl s240).

14. Ozkurt YB, Sengör T, Evciman T, Haboğlu M. Refraction, intraocular pressure and anterior chamber depth changes after Nd:YAG laser treatment for posterior capsular opacification in pseudophakic eyes. Clin Exp Optom. 2009;92(5):412-415.

15. Zhang Q, Jin W, Wang Q. Repeatability, reproducibility, and agreement of central anterior chamber depth measurements in pseudophakic and phakic eyes: optical coherence tomography versus ultrasound biomicroscopy. J Cataract Refract Surg. 2010;36(6):941-946.

16. Kriechbaum K, Findl O, Kiss B, Sacu S, Petternel V, Drexler W. Comparison of anterior chamber depth measurement methods in phakic and pseudophakic eyes. J Cataract Refract Surg. 2003;29(1):89-94.

17. Findl O, Kiss B, Petternel V, et al. Intraocular lens movement caused by ciliary muscle contraction. J Cataract Refract Surg. 2003;29(4): 669-676.

18. Tsorbatzoglou A, Németh G, Máth J, Berta A. Pseudophakic accommodation and pseudoaccommodation under physiological conditions measured with partial coherence interferometry. $J$ Cataract Refract Surg. 2006;32(8):1345-1350.
Clinical Ophthalmology

\section{Publish your work in this journal}

Clinical Ophthalmology is an international, peer-reviewed journal covering all subspecialties within ophthalmology. Key topics include: Optometry; Visual science; Pharmacology and drug therapy in eye diseases; Basic Sciences; Primary and Secondary eye care; Patient Safety and Quality of Care Improvements. This journal is indexed on Submit your manuscript here: http://www.dovepress.com/clinical-ophthalmology-journal

\section{Dovepress}

PubMed Central and CAS, and is the official journal of The Society of Clinical Ophthalmology (SCO). The manuscript management system is completely online and includes a very quick and fair peer-review system, which is all easy to use. Visit http://www.dovepress.com/ testimonials.php to read real quotes from published authors. 